\title{
Explaining anomalies in SAR and scatterometer soil moisture retrievals from dry soils with sub-surface scattering
}

Article

Accepted Version

Morrison, K. and Wagner, W. (2020) Explaining anomalies in SAR and scatterometer soil moisture retrievals from dry soils with sub-surface scattering. IEEE Transactions on Geoscience and Remote Sensing, 58 (3). pp. 2190-2197. ISSN 0196-2892 doi: https://doi.org/10.1109/TGRS.2019.2954771 Available at https://centaur.reading.ac.uk/87367/

It is advisable to refer to the publisher's version if you intend to cite from the work. See Guidance on citing.

To link to this article DOI: http://dx.doi.org/10.1109/TGRS.2019.2954771

Publisher: IEEE Xplore

All outputs in CentAUR are protected by Intellectual Property Rights law, including copyright law. Copyright and IPR is retained by the creators or other copyright holders. Terms and conditions for use of this material are defined in the End User Agreement.

www.reading.ac.uk/centaur 
Central Archive at the University of Reading

Reading's research outputs online 


\title{
Explaining Anomalies in SAR and Scatterometer Soil Moisture Retrievals from Dry Soils with Sub-Surface Scattering
}

\author{
K. Morrison, Member, IEEE, and W. Wagner, Senior Member, IEEE
}

\begin{abstract}
This paper presents the results of a laboratory investigation to explain anomalously-high soil moisture estimates observed in retrievals from SAR and scatterometer backscatter, affecting extensive areas of the world associated with arid climates. High resolution $\mathrm{C}$-band tomographic profiling was applied in experiments to understand the mechanisms underlying these anomalous retrievals. The imagery captured unique highresolution profiles of the variations in the vertical backscattering patterns though a sandy soil with moisture change. The relative strengths of the surface and sub-surface returns were dependent upon both soil moisture and soil structure, incidence-angle, and polarization. Co-polarised returns could be dominated by both surface and sub-surface returns at times, whereas cross-polarised returns were strongly associated with sub-surface features. The work confirms suspicions that anomalous moisture estimates can arise from the presence of sub-surface features. Diversity in polarization and incidence angle may provide sufficient diagnostics to flag and correct these erroneous estimates, allowing their incorporation into global soil moisture products.
\end{abstract}

Index Terms - soil moisture anomalies, radar, radar imaging, sub-surface scattering, synthetic aperture radar.

\section{INTRODUCTION}

A ccurate knowledge of soil moisture is fundamental in understanding the Earth system. It is a control in the global hydrological cycle through the exchange of energy fluxes between the land and atmosphere [1]. Amongst other things, soil moisture estimates are important for agricultural management, flood and drought prediction, and rain precipitation models [2-4]. The importance of reliable knowledge of soil moisture was recognized in 2010 through its identification as an essential climate variable in the Global Climate Observing System. Since 2012, work within the European Space Agency's (ESA) Climate Change Initiative (CCI) Soil Moisture, has derived a multi-decadal, global

The authors acknowledge for funding of this work under the European Space Agency's Climate Change Initiative: Soil Moisture, contract 4000112226/14/I-NB.

K. Morrison is with the Department of Meteorology, University of Reading, P.O. Box 243, Reading RG6 6BB, UK (e-mail: k.morrison@reading.ac.uk).

W. Wolfgang is with the Department of Geodesy and Geoinformation, TU Wien, Gusshausstr. 27-29, Vienna 1040, Austria (e-mail: Wolfgang.Wagner@geo.tuwien.ac.at) satellite-observed soil moisture dataset which rests on soil moisture retrievals based on both passive and active microwave systems [5]. This has been to understand the longterm dynamics of soil moisture in the coupled water, energy, and carbon cycles over land.

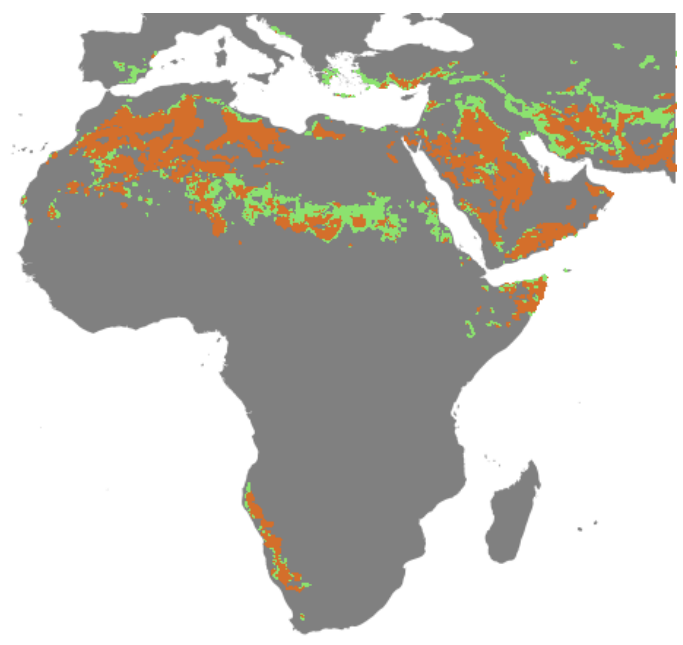

Persisent Temporary

Fig. 1. Regions associated with sub-surface scattering across Africa, southern Europe, and middle-/near-east. They are identified through an anti-correlation between the ASCAT-derived with GLDAS moisture outputs. The regions are further broken down into those which persist all year, and those which are seasonal

Whilst the work has successfully retrieved the seasonal dynamics of moisture across large regions of the globe, problematic regions exist in the active soil moisture retrievals. Fig. 1 shows the presence of backscatter-derived moisture anomalies across Africa, southern Europe, and the middle/near-east. They are identified by anti-correlations between ASCAT soil moisture products [6-11] and those from the Global Land Data Assimilation System (GLDAS) which combines satellite- and ground-based data with land surface modeling [12]. Large anomalies are associated with a region centered over Algeria, and another which overlies a large part of the Arabian Peninsula. The retrieval of soil moisture from radar backscatter is based on the premise that backscatter increases as the soil becomes wetter due to the increase of dielectric contrast at the air-soil boundary [13-15]. Anticorrelations arise when the soil shows an increase in 


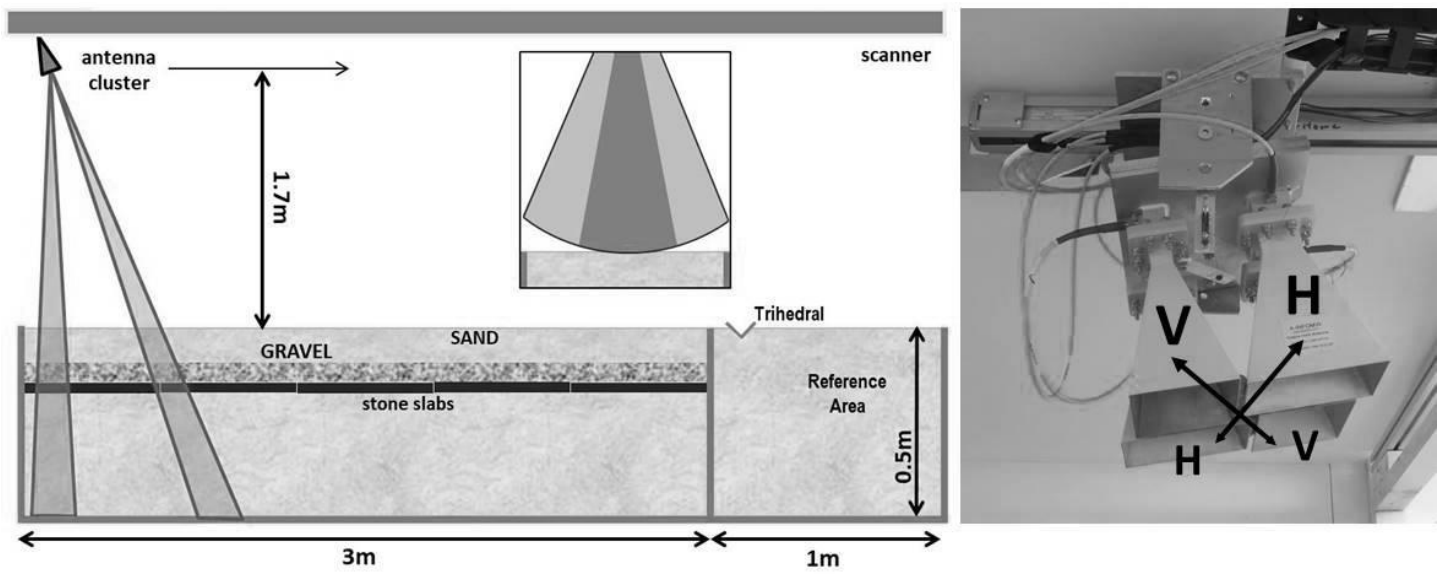

Fig. 2. (Left) Schematic of the radar measurement system (not to scale) showing the linear scanner placed centrally above the $4 \mathrm{~m}$ long trough. The set-up for Experiment 1 is shown, with a $5 \mathrm{~cm}$-thick gravel layer overlain by an $11 \mathrm{~cm}$-thick sand layer. The inset displays the curvature of the real beam across the $1 \mathrm{~m}$-wide trough; the darker region indicates the limit of the (two-way) $3 \mathrm{~dB}$ beamwidth. (Right) Photograph of the antenna cluster, tilted forward at $10^{\circ}$. Each component co-polar pair is offset diagonally about the common phase centre.

backscatter with decreasing moisture. Some of the anomalies persist continuously, whereas others are only seasonal. All anomalous regions are associated with geographical locations which can be expected to experience hot, arid conditionsThere is strong evidence from both measurements and modeling to believe that the backscatter moisture anomalies arise when the soil incorporates brightly reflecting sub-surface features, such as a rocky layer overlain by a shallow soil $[16,17]$. In very dry conditions, the sub-surface reflection can be the dominant return. After rain, the increase in backscatter from the wetter, brighter soil surface does not offset the loss of the sub-surface signal, primarily from increased attenuation through the soil layer. Reference [16] used modeling informed by laboratory measurements to investigate the nature of backscatter moisture anomalies in such conditions. These indicated large fluctuations in backscatter on the order of $10 \mathrm{~dB}$ were possible when soils went from dry to wet states.

In this paper we report on a series of laboratory radar measurements carried out on drying sandy soils in low moisture conditions representative of hot, arid regions associated with backscatter moisture anomalies. The study data is unique in that it provides imagery which allows direct viewing of the internal dynamics of backscatter within a soil in response to moisture changes. The moisture-backscatter results are presented against soil structure, imaging geometry, and polarization.

\section{MEASUREMENTS}

\section{A. Laboratory Details}

The experimental data for this study were collected at the University of Reading using at the Reading Radar Facility to provide a series of indoor microwave measurements. As detailed in Fig. 2, a linear scanner is centrally located down the length of a $4 \mathrm{~m}(1) \times 1 \mathrm{~m}(\mathrm{w}) \times 0.5 \mathrm{~m}(\mathrm{~h})$ soil trough. The trough is constructed from plywood with no metal fasteners in order to avoid unwanted radar returns. The microwave subsystem consists of an HP 8720ES Vector Network Analyser connected to antennas by means of flexible coaxial cable runs. A cluster of four C-band antennas is mounted on the scanner, pointing forward and downwards at $10^{\circ}$ from nadir. The cluster comprises a VV transmit-receive pair, and similarly for $\mathrm{HH}$. The component antennas in a pair are offset from each other by $45^{\circ}$, which introduces small bi-static angles of up to $8^{\circ}$ into the co-pol. measurements. Whilst the $\mathrm{VV}$ and $\mathrm{HH}$ pairs are arranged around a common phase center, the $\mathrm{VH}$ antenna pair is offset $8.4 \mathrm{~cm}$ from this in the acrosstrack direction. Each antenna had a $3 \mathrm{~dB}$ real beamwidth of $23^{\circ}$ in both the along- and across-track directions. Scanner movement is by a computer-controlled servomotor which allows accurate $(<0.2 \mathrm{~mm})$ mechanical positioning of the antennas, providing exact, repeatable measurements. All image scans in this study were collected over a $3.51 \mathrm{~m}$ aperture using 235 aperture points and a sampling interval of $15 \mathrm{~mm}$. At each sample position, 201 equally-spaced frequency points were collected over a $0.5 \mathrm{GHz}$ bandwidth across a frequency range of 5.75-6.25GHz. Each scan took just over 6 minutes to

collect. The antennas are momentarily static whilst each RF measurement is made. The system can be automatically set to acquire scan sequences at precisely timed intervals. This enables unsupervised regular sampling over long periods of time to study the slowly evolving scattering behavior of a scene.

\section{B. Soil Study}

The soil used in the investigation was fine, kiln-dried sand. Two different set-ups were used: Experiment 1 used a $5 \mathrm{~cm}-$ thick gravel layer below a sand layer. The gravel was additionally underlain by five $90 \mathrm{~cm} \times 60 \mathrm{~cm} \times 4 \mathrm{~cm}$ paving slabs, placed horizontally. The surface of the gravel was left rough such that the depth of the sand varied between $10-12 \mathrm{~cm}$ over the gravel. The surface of the sand, however, was smoothed off level with the trough edges. For Experiment 2, the gravel that had formed a sub-surface layer in Experiment 1 was instead used to create a $10 \mathrm{~cm}$ deep, randomly-mixed, sand-gravel mixture in the proportions $50: 50$ by volume, and without the paving slabs present. This time, the surface of the 


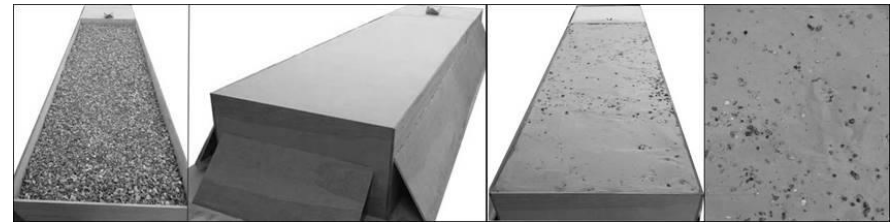

Fig. 3. The leftmost two figures display the preparation of the soil set-up for Experiment 1 showing the gravel layer and the finished result after adding an $11 \mathrm{~cm}$-thick layer of sand above the gravel. The sand surface was smoothed flat, level with the trough edges. The reference trihedral is visible within the undisturbed soil region occupying the final meter of the trough. The rightmost two figures show the rough surface of the randomly-mixed soil in Experiment 2 , including a zoomed view to highlight the presence of stones.

soil was left rough. The final $1 \mathrm{~m}$ length of the trough was used as a reference area in both experiments, and was separated from the experiment area by a vertical plywood sheet. The area contained a homogeneous sand sample throughout the $0.5 \mathrm{~m}$ depth, as well as a surface-placed reference corner reflector. Fig. 3 shows photographs taken during the set-ups of the two experiments.

The two soil set-ups were chosen as indicative of scenarios in the real world that would likely invoke opposite biases in radar responses. Experiment 1 presented an idealized representation of a layered soil with a flat surface overlying a rough sub-surface layer. The smooth air-soil interface should be an effective specular reflector, such that away from nadir it provides little backscatter. The rough surface of the buried layer, in contrast, should provide backscatter over a much greater range of viewing geometries. In contrast, Experiment 2 presented a rough air-surface and had no buried gravel layer distinct from the surface. Thus, we expected Experiment 1 to be highly favorable to providing a backscatter-moisture anomaly, whereas for Experiment 2 the signal might be much less clear due to stronger air-surface returns at viewing geometries well away from nadir.

Experiment 1 proceeded by the addition of a $4 \mathrm{~mm}$ depth of water (corresponding to the addition of 12 litres) across the $3 \mathrm{~m} \times 1 \mathrm{~m}$ sample area, and subsequent monitoring whilst drying without disturbance to the scene. The $4 \mathrm{~mm}$ of water was added over a 2-hour interval in four $1 \mathrm{~mm}$ steps, with collection of radar images in between additions. Water was manually added using a Hozelock Standard 5-litre Pressure Sprayer which provided a fine spray that did not disturb the surface profile of the sand. Following completion of the water addition, the data were collected at hourly intervals over the first 4 days, and then relaxed to 2-hour intervals for the rest of the collection. The experiment collected data over 15.2 days, although there are gaps in the data of $0.71,4.49,1.11$ days starting at 4.28, 7.48, and 12.98 days, respectively. Experiment 2 used the addition of a $3.3 \mathrm{~mm}$ depth of water to the sand (corresponding to the addition of 10 litres) over a 70 minute interval, using three additions of $1 \mathrm{~mm}, 1 \mathrm{~mm}$, and $1.3 \mathrm{~mm}$. There is then a continuous data record collected at 4 hour intervals over 10.7 days. No record was made of soil moisture variations over the course of the experiment, other than noting the depths of water added at the start of the experiment.

\section{Radar Imaging}

The radar imagery in this study was collected using tomographic profiling (TP) $[18,19]$. TP does not provide a true tomographic reconstruction [20], but the presented result has similarity to that derived from tomographic schemes - namely a $2 \mathrm{D}$ vertical backscattering profile through a volume. The TP process requires data collected in a similar fashion to conventional SAR imaging across a synthetic aperture, but with antennas rotated $90^{\circ}$ such that they look along the direction of platform travel, and so only image a transect directly below the scanner. Post-measurement, the TP scheme sharpens the wide real antenna beam across a chosen subaperture length to provide a 'sounding profile' of the backscatter through a soil, as shown in Fig. 2. The beam is steered to the desired look angle in the along-track direction by applying a suitable phase ramp across the sub-aperture elements. Thus, post-measurement, a single scan provided image reconstructions over the incidence angle range $0-25^{\circ}$. The steep viewing geometries maximize the area of the trough that can be imaged, as well as providing the highest vertical resolutions [18]. Each sub-aperture provides a slice through the soil at the chosen angle, and repeating the process at successive along-track offsets (at the sample interval of $15 \mathrm{~mm}$ ) builds up an image of the scene below the scanner transect. In the slant range direction the resolution is set by the frequency bandwidth. The vertical and horizontal resolutions eventually realized are a combination of contributions from the sharpened and real across-track beams, incidence angle, and frequency bandwidth.

There are some limitations on the use of the TP scheme. As for all phased arrays, the synthesized beam broadens and distorts as the beam is steered away from nadir, here limiting the study to an upper angle of $25^{\circ}$. It correctly allows a comparison of the magnitude of the changes within drying curves for different incidence angle, but not of their absolute

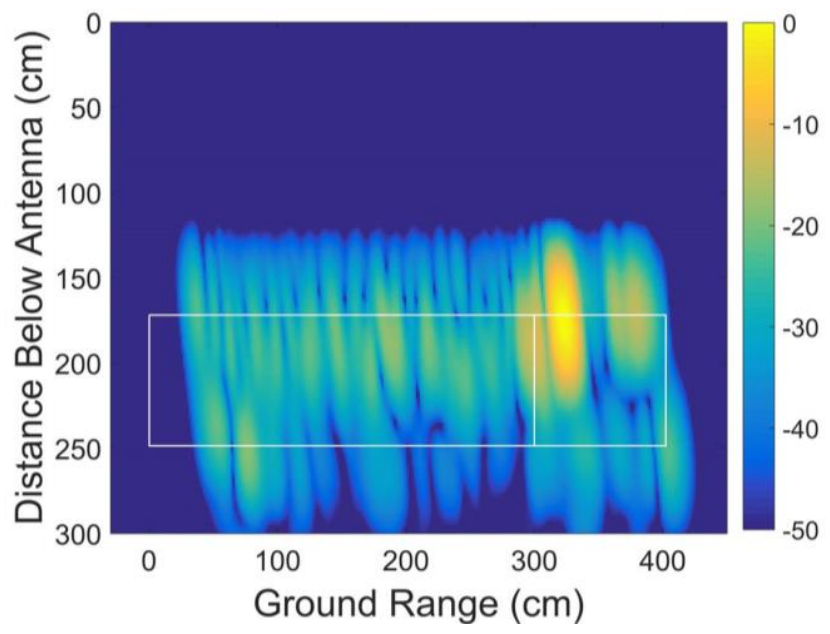

Fig. 4. Experiment 1: TP VV image using a $10^{\circ}$-shear reconstruction for the soil prior to addition of water. The outline of the soil trough is shown, extended by a factor $\sqrt{\epsilon_{r}}$ in range, with the reference area delineated on the right. The bright feature at $325 \mathrm{~cm}$ ground range within the reference area is the reference trihedral. The image is auto-normalized over $50 \mathrm{~dB}$. 


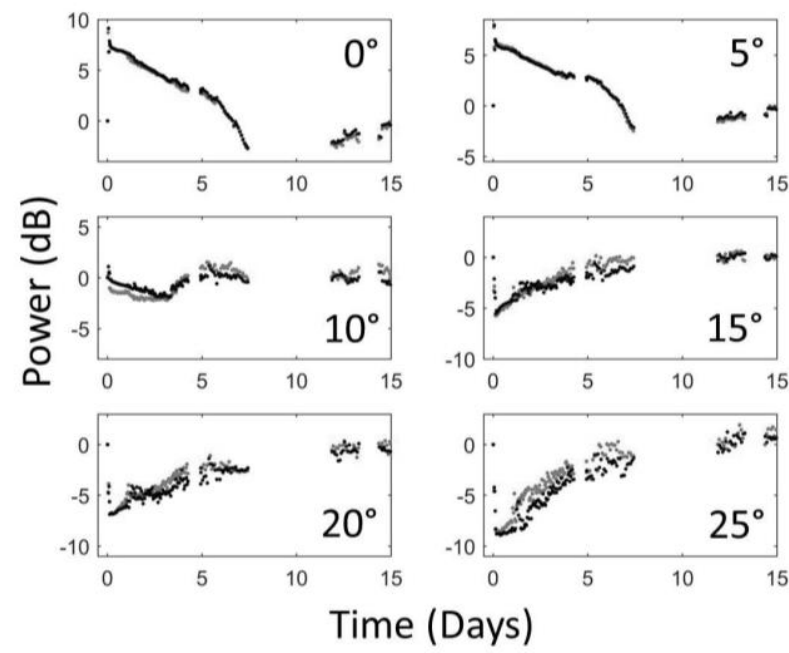

Fig. 5. Experiment 1: The co-polar VV (black) and HH (gray) backscatter drying curves for incidence angles $0^{\circ}, 5^{\circ}, 10^{\circ}, 15^{\circ}, 20^{\circ}, 25^{\circ}$. All curves are shown over a $14 \mathrm{~dB}$ power range. The first data point - corresponding to dry soil before the addition of water - was set to $0 \mathrm{~dB}$ in each plot. The next four points correspond to the successive addition of $1 \mathrm{~mm}$ depths of water.

backscatter values. This limitation arises primarily due to uncertainties in the near field antenna beam pattern illumination. A constant-length $180 \mathrm{~cm}$-long study region along the trough was utilized in the analysis. The restriction to a $180 \mathrm{~cm}$ sub-zone from the $300 \mathrm{~cm}$-long soil study zone comes from the need to avoid 'edge' effects in the image reconstructions, and both the trough edge directly beneath the scan start, and the reference area past $300 \mathrm{~cm}$ at the other end of the trough. There was up to a $20 \mathrm{~cm}$ difference in the start position of the $180 \mathrm{~cm}$ region across the incidence-angle reconstructions. Shifting the start positions by $\pm 10 \mathrm{~cm}$ produced no statistically-relevant changes in the drying curves presented in the analyses below.

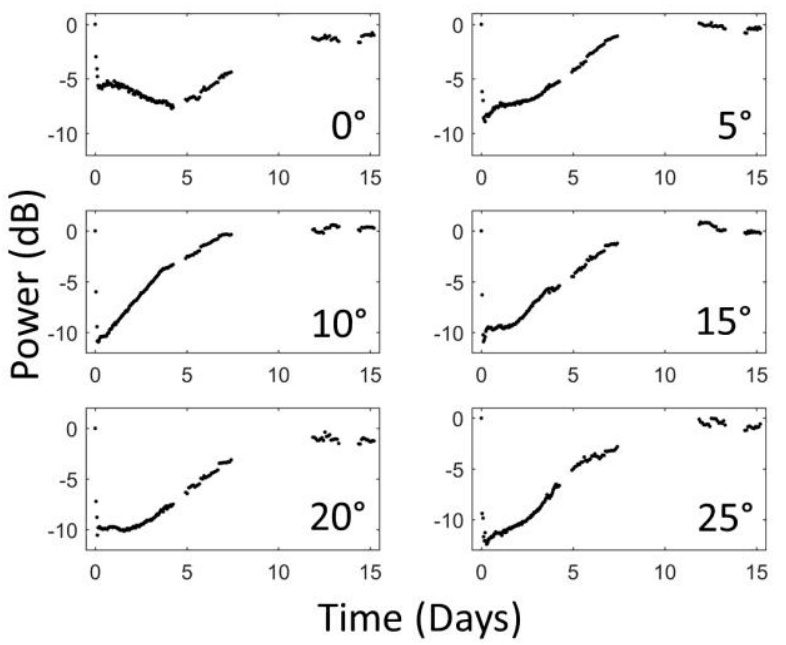

Fig. 6. Experiment 1: Cross-polarised $\mathrm{VH}$ backscatter drying curves for incidence angles $0^{\circ}, 5^{\circ}, 10^{\circ}, 15^{\circ}, 20^{\circ}, 25^{\circ}$. All curves are shown over a $14 \mathrm{~dB}$ power range. The first data point - corresponding to dry soil before the addition of water - was set to $0 \mathrm{~dB}$ in each plot. The next four points correspond to the successive addition of $1 \mathrm{~mm}$ depths of water.

\section{Data Sets}

The $0.5 \mathrm{GHz}$ bandwidth provided a free-space slant range of 30cm. Fig. 4 shows the VV TP image of the dry soil from Experiment 1 just before the addition of water, reconstructed for an incidence angle of $10^{\circ}$. The imagery used a free-space reconstruction, such that sub-surface distances are extended by a multiplicative factor close to $\sqrt{ }\left(\epsilon_{-} r\right)$, where $\epsilon_{-} r$ is the dielectric constant relative to air. Thus, the apparent soil depth in the trough in free-space reconstructions is $80 \mathrm{~cm}$ for the dry soil case, and greater with wetter soil. The $11 \mathrm{~cm}$-deep gravel layer will appear at least $17 \mathrm{~cm}$ below the surface. Wavelength compression within the soil [21] improves the resolution by a factor of $1 / \sqrt{ }\left(\epsilon_{-} r\right)$. A previously measured $\epsilon_{-} r=2.50 \pm 0.05$ for the dry sand leads to a final resolution within the dry soil of around $25 \mathrm{~cm}$ after Hamming windowing during processing. The resolution is sufficient to blend the surface sand, gravel, and stone slabs into a single unresolved return, whilst still allowing separation with the trough base response to avoid contamination. Because only small amounts of water were added during the experiments, the wavelength compression factor was little changed during the study and the features always remained unresolved in the imagery. The reference area was left dry, such that surface and sub-surface changes are minimal (with small changes due to slight water contamination of the area during water addition to the experimental area). The resolution in the along-track direction was kept high, using a $45 \mathrm{~cm}$ sub-aperture. This provides for a resolution horizontally along the trough of close to $15 \mathrm{~cm}$ after windowing. The aperture processing has no effect in the across-track direction, however. This is defined by the (twoway) $3 \mathrm{~dB}$ real beamwidth, which was $50 \mathrm{~cm}$ at the soil surface.

\section{RESULTS}

\section{A. Experiment 1: Layered}

Fig. 5 summarizes the temporal co-pol. VV and $\mathrm{HH}$ backscatter behaviours of the drying soil for Experiment 1 over the incidence angle range $0^{\circ}-25^{\circ}$, at $5^{\circ}$ intervals. The curves have been corrected for any system drifts by referencing them against the reference trihedral. The first point for each curve is set to $0 \mathrm{~dB}$ and represents the dry soil before addition of water. Each point on the graph is derived from the global amplitude characterizing an individual TP image. The $\mathrm{HH}$ and VV curves are generally very similar, particularly for $0^{\circ}$ and $5^{\circ}$. There are short intervals for $10^{\circ}$ and above where there are small differences. On average, the difference in the backscatter curves between the two polarisations was $0.3 \mathrm{~dB}$, comparable to the estimated channel imbalance error of $\pm 0.3 \mathrm{~dB}$ between $\mathrm{VV}$ and $\mathrm{HH}$. As such, $\mathrm{VV}$ and $\mathrm{HH}$ are regarded as effectively displaying the same behaviour across all soil structures and moisture states. Whilst small differences were occasionally seen which were greater than the formal error estimate between the channels, we cannot rule out these differences arising from near-field effects - primarily from the small bi-static angles associated with the collection geometry.

The curves all show anomalous drying behavior at some stage, inasmuch as backscatter increased after some point in time as soil moisture decreased. Nadir $0^{\circ}$ viewing initially produces a conventional decrease in backscatter as the soil 


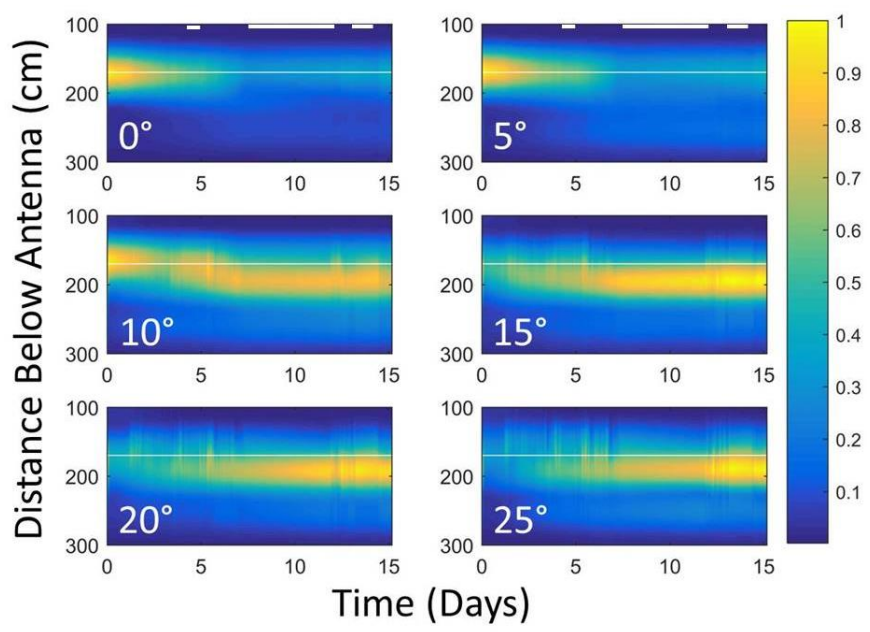

Fig. 7. Experiment 1: Cross-sectional views of the backscatter amplitude through the soil for $\mathrm{VV}$ polarisation and incidence angles $0^{\circ}, 5^{\circ}, 10^{\circ}, 15^{\circ}, 20^{\circ}$, $25^{\circ}$. The expected position of the surface is shown by the horizontal white line. The interpolated regions are indicated by the white bars at the top of each figure column. Each plot is auto-normalised over the range 0-1.

dries, before it eventually displayed an anomalous upturn. A data gap does not permit viewing of the point of upturn, or whether the observed $10.3 \mathrm{~dB}$ backscatter variation would have been larger with a complete data set. The curve for $5^{\circ}$ shows a similar behavior to the $0^{\circ}$ case, although with a reduced total variation. Whilst the $0^{\circ}$ and $5^{\circ}$ cases showed immediate increases in backscatter with the increasing addition of water, this reversed for $10^{\circ}$ and becomes more pronounced for higher angles, such that $25^{\circ}$ saw a diminution of $9.4 \mathrm{~dB}$ with the addition of water. That the backscatter curves return very close to their starting values is highly indicative that the soil was completely dry at the end of the experiment, confirmed by manual inspection.

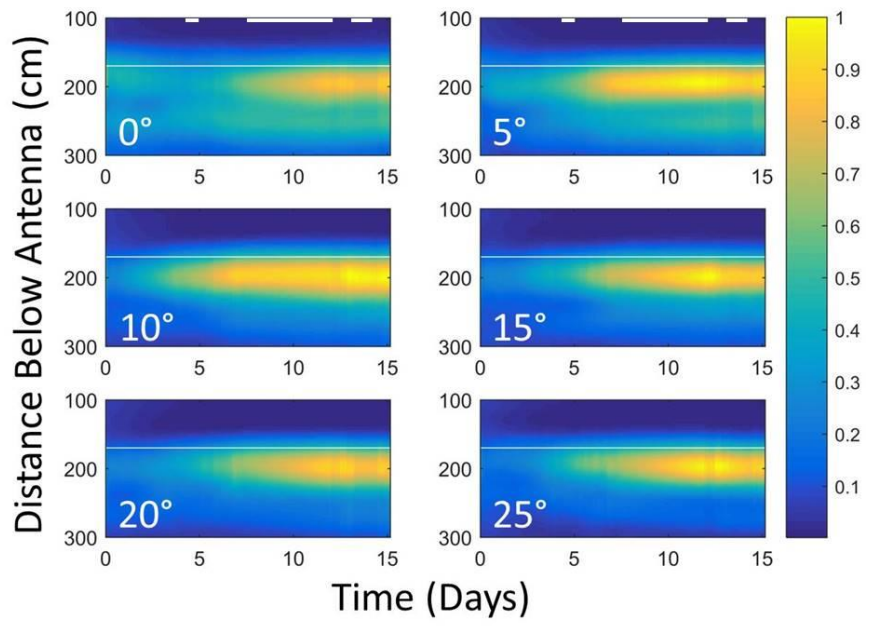

Fig. 8. Experiment 1: Cross-sectional views of the backscatter through the soil for $\mathrm{VH}$ polarisation and incidence angles $0^{\circ}, 5^{\circ}, 10^{\circ}, 15^{\circ}, 20^{\circ}, 25^{\circ}$. The expected position of the surface is shown by the horizontal white line. The interpolated regions are indicated by the white bars at the top of each figure column. Each plot is auto-normalised over a 0-1 range.

The cross-pol. VH drying curves are strongly divergent from the co-pol. case, most notably at steep incidence angles. Fig. 6 shows that the curves all respond to the addition of water with an immediate drop in backscatter, which then recovers during the drying process. For the $20^{\circ}$ and $25^{\circ}$ cases, this leads to drops of $11 \mathrm{~dB}$ and $12 \mathrm{~dB}$, respectively. In contrast to the co-pol. case, the drying curves are anomalous at all incidence angles.

Fig. 7 is a summary of the backscatter amplitude pattern through the soil for the VV case (the HH case is not shown, but looks very similar). It was created by summing horizontally along each pixel row to compress each image down to a single column, then stacking them sequentially in time. In addition, a simple linear interpolation was carried out to fill in the gaps evident in the drying curves in Fig. 5. Whilst this cannot be expected to properly recover the missing data, especially at $0^{\circ}$ and $5^{\circ}$ degrees, the unbroken image does aid the eye in interpretation of the temporal changes in the depth positioning of the dominant backscatter returns. As would be expected, the timings of the backscatter maxima and minima reflect those visible in Fig. 5. For the steep-angle cases of $0^{\circ}$ and $5^{\circ}$, the dominant return always remains at the surface. Close to nadir, the smooth surface will be very efficient in returning a strong, mirror-like reflection back to the antennas. The separate weak feature at around $250 \mathrm{~cm}$ depth corresponds to the base of the box. The $10^{\circ}$ case shows a strong and dominant surface return for the first three days after addition of water. However, between Days 3-7, the position of the dominant backscatter shows a slow drift from the surface to the buried gravel layer as the summation of the dimming surface return with the brightening gravel return draws the backscatter downwards. The $15^{\circ}$ through $25^{\circ}$ cases are dominated by the sub-surface return. The $15^{\circ}$ case still shows a drift downwards, albeit from a much weaker surface return. A similar effect is also just visible in the $20^{\circ}$ case, but for the $25^{\circ}$ case only an increasing sub-surface return is evident.

Fig. 8 shows the corresponding result for the VH case. The $5^{\circ}$ and above cases display the same story of a strengthening sub-surface return in the absence of a defined surface return. Only the $0^{\circ}$ case displays an interval (Days 0-3) where the dominant backscatter comes from a depth not immediately associated with the gravel layer; rather it sits at a shallower depth. This is assumed to arise from the contribution of the strong specular reflection present at nadir. It fades as the moisture decrease at the surface and is gradually replaced by a strengthening sub-surface return at the position of the gravel layer.

\section{B. Experiment 2: Mixed}

Fig. 9 shows the VV and VH drying curves for the mixed gravel-sand soil (the $\mathrm{HH}$ and VV curves display very similar behaviours over all angles, so only the VV results are reported here). The results are notably different from the corresponding results associated with the layered soil in Experiment 1. The co-pol. VV response for all angles is a sudden jump in backscatter of around $5 \mathrm{~dB}\left(2.5 \mathrm{~dB}\right.$ in the $25^{\circ}$ case), followed by a rapid decline. For the $0^{\circ}$ through $15^{\circ}$ cases, after the third day the backscatter curves are essentially flat. For the shallower angles, and the $25^{\circ}$ case in particular, the curves display further changes leading to an increase in backscatter. 


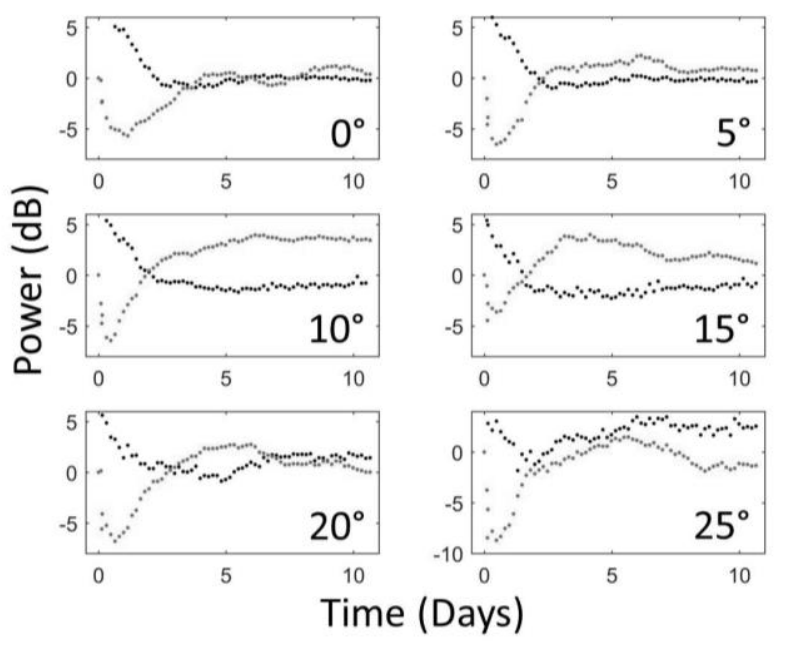

Fig. 9. Experiment 2: VV (black) and VH (gray) backscatter drying curves for the mixed sand-gravel soil at incidence angles $0^{\circ}, 5^{\circ}, 10^{\circ}, 15^{\circ}, 20^{\circ}, 25^{\circ}$. All curves are shown over a $14 \mathrm{~dB}$ power range. The first data point corresponding to dry soil before the addition of water - was set to $0 \mathrm{~dB}$ in each plot. The next three points correspond to the successive addition of $1 \mathrm{~mm}$, $1 \mathrm{~mm}$, and $1.33 \mathrm{~mm}$ depths of water. The dry sand returns for VH were $21.8 \mathrm{~dB},-20.2 \mathrm{~dB},-16.9 \mathrm{~dB},-16.2 \mathrm{~dB},-13.4 \mathrm{~dB},-11.1 \mathrm{~dB}$ down on the $\mathrm{VV}$ returns for $0^{\circ}, 5^{\circ}, 10^{\circ}, 15^{\circ}, 20^{\circ}, 25^{\circ}$, respectively.

The cross-pol. VH curves are largely in opposition to the copol. results; the initial jump seen in VV with the addition water is matched by a roughly equivalent dimming in $\mathrm{VH}$ (but enhanced in the $25^{\circ}$ case). The rapid backscatter declines are followed after the third day by flatter curves. Compared to the drying curves in Figs. $5 \& 6$ for Experiment 1, they are more discrepant with regard to returning to their starting values.

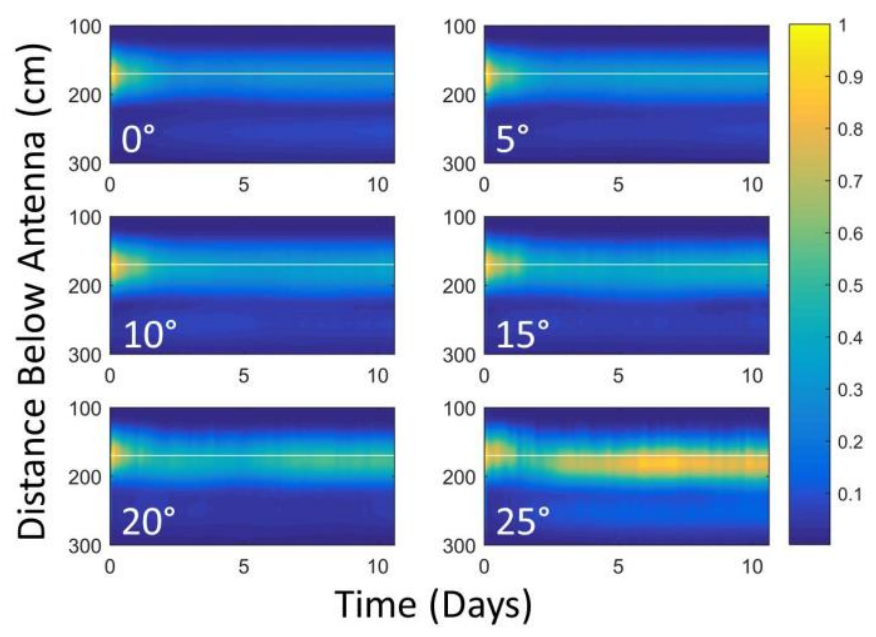

Fig. 10. Experiment 2: Cross-sectional views of the backscatter amplitude through the soil for $\mathrm{VV}$ polarisation and incidence angles $0^{\circ}, 5^{\circ}, 10^{\circ}, 15^{\circ}, 20^{\circ}$, $25^{\circ}$. The expected position of the surface is shown by the horizontal white line. Each plot is auto-normalised over a 0-1 range.

Fig. 10 shows cross sectional views of the VV backscatter pattern through the drying soil against incidence angle. For the $0^{\circ}$ case the return stays at the surface for the duration of the experiment. Whilst all incidence angles display a strong, dominant return at the surface over the first two days, the $15^{\circ}$ case begins to show the position of the dominant return is

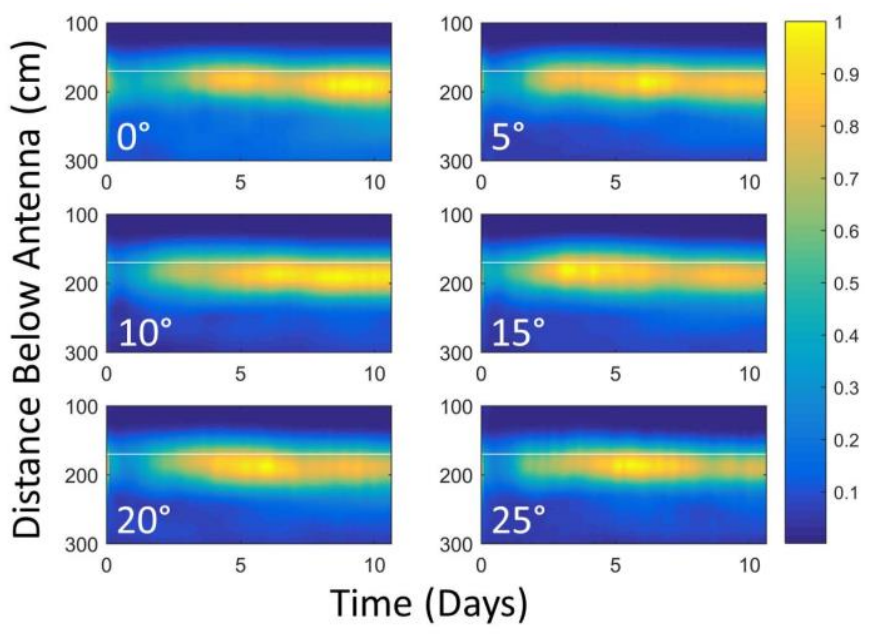

Fig. 11. Experiment 2: Cross-sectional views of the backscatter amplitude through the soil for $\mathrm{VH}$ polarisation and incidence angles $0^{\circ}, 5^{\circ}, 10^{\circ}, 15^{\circ}, 20^{\circ}$, $25^{\circ}$. The expected position of the surface is shown by the horizontal white line. Each plot is auto-normalised over a 0-1 range.

slightly below the surface. This becomes increasingly obvious with increasing incidence angle. The $25^{\circ}$ case shows that the position of dominant return switches from surface to subsurface over the course of two days between days 1 to 3 . The sub-surface return is centered around $182 \mathrm{~cm}$, corresponding to an apparent depth of $10 \mathrm{~cm}$. Correcting for the range extension effect of the dielectric medium, this translates to an effective scattering depth of around 5-6cm - around the mid-depth point of the gravel-sand layer. Fig. 11 shows the cross sectional views for $\mathrm{VH}$. The addition of water causes a reduction in backscatter, which continues to reduce and reaches a minimum a day after the addition for the $0^{\circ}$ case, and around half a day for the other angles. The dominant return always originates from sub-surface.

\section{DISCUSSION}

Current soil moisture retrievals from SAR and scatterometer data rely on bare soil surface backscatter models that predict an increase in backscatter with increasing soil moisture. These models are hence unable to correctly describe the interaction of the radar waves with the soil when sub-surface scattering becomes important. Our laboratory experiments showed the presence and characteristics of the backscatter moisture anomalies to be strongly dependent upon both soil structure and radar imaging parameters. For the layered case of Experiment 1, the co-pol. drying curve was anomalous above $10^{\circ}$, and increasingly so for rising incidence angles. Figs. 5 and 7 shows that the presence of anomalies could be clearly associated with times when the sub-surface returns were dominant, and that the strengths of the backscatter anomalies increased with incidence angle. For the cross-pol. case the sub-surface return was always the dominant return, such that the anomalies are more obvious and present over all angles. Addition of water in these cases caused immediate, strong diminutions in backscatter, which then recovered during the drying progress.

For the mixed soil, the presence of backscatter anomalies 


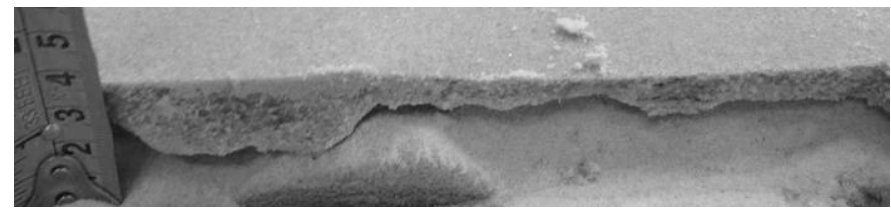

Fig. 12. Excavation showing the maximum depth extent of the wet zone following the addition of $3.3 \mathrm{~mm}$ of water.

was much reduced. In the co-pol. results the $20^{\circ}$ case represents a transition state between the insensitive lower angles and the obvious anomaly present in the $25^{\circ}$ case. Fig. 10 shows that this tied up with the emergence of a dominant sub-surface return. The flat behaviour of the $0^{\circ}-15^{\circ}$ curves indicated a lack of sensitivity to changes in the soil after day 3 . We would still expect the soil to be changing in moisture content after these days, as indicated by further changes at higher-incidence angles and $\mathrm{VH}$. If the stones at the surface and near-surface dominated the return after day 3 for these angles, then the radar could be insensitive to small changes associated with further moisture variations. Fig. 11 shows that the $\mathrm{VH}$ return for the mixed soil was always dominated by the sub-surface return. The strong anomalies present in the $\mathrm{VH}$ pol. at the start were replaced by more complex behaviours towards the end of the drying process. These may be associated with speckle effects, differential drying, and physical changes in the soil caused by the addition of water, and which persisted after the loss of the moisture.

Fig. 12 is an excavation of the soil several hours after the addition of $3.3 \mathrm{~mm}$ of water to the dry sand, carried out in the reference area of the trough after completion of the main study. It shows that the moisture would have only travelled down to a depth of $1-2 \mathrm{~cm}$ in both Experiments 1 and 2. There was a sharp wetting front between the upper wet and dry sand below. The rough profile of the surface at the wetting front can be expected to be efficient at backscattering. Locally within the wet zone, the moisture would have been close to $20 \%$ volumetric water content. Although attenuated, a scattered signal here might constitute a noticeable and varying component throughout the drying process if a sharp dielectric contrast is maintained at the wetting interface. Also, although many of the drying curves returned close to their initial prewetting dry value, this was not the case for all the curves. Whilst the addition of water was unlikely to have disturbed the surface profile, at the end of the experiment the soil displayed weak and patchy cementation within the previously wet zone which may account for these differences - especially if a soil maintains a memory of the rough surface at the wetting front interface.

Fig. 13 attempts to summarize the different responses from the two soil structure cases. For Experiment 1, the combination of a very flat surface overlying a rough subsurface layer can be expected to be favourable to backscatter anomalous behaviour through the biased detection of the subsurface return over the surface return. The smooth, planar surface will be an effective forward scatterer, increasingly so away from nadir - in contrast to the rough, random surface of the sub-surface layer. This bias is further enhanced for the $\mathrm{VH}$

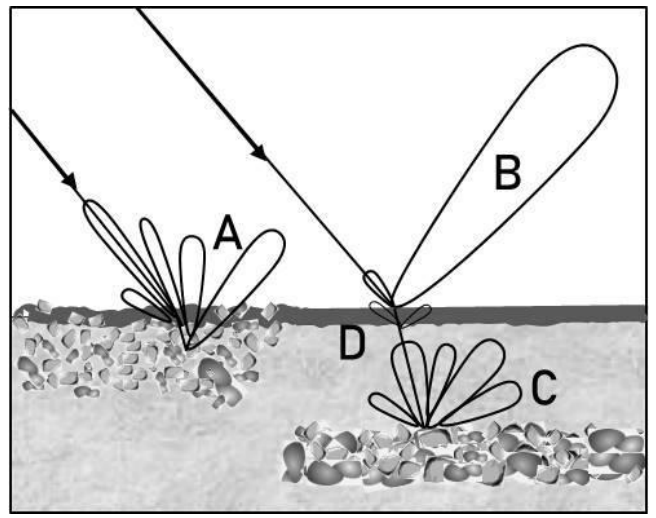

Fig. 13. Summary of the scattering from the various soil types in a crosssectional view through a soil. Left shows that the rough-surfaced mixed soil provides backscattering from both the surface and volume (A). Right shows that the smooth-surfaced layered soil forward scatters strongly (B), whereas the rough-surfaced buried layer provides backscatter (C). The figure also shows that wetting of the surface can cause the appearance of a 'rough surface interface' at the wetting front which can backscatter (D).

case, whereby a flat surface does not give rise to a cross-pol. response, but the gravel layer does [22,23]. For the mixed soil, returns can be expected to arise throughout the soil volume. In contrast to the soil structure of Experiment 1, here the rough surface gives rise to a significant surface return even away from nadir. This is sufficient to mask a clear sub-surface signal in the co-pol. case, and to confuse the response in the cross-pol. case.

Whilst the laboratory study was necessarily confined to the steep angles $0^{\circ}-25^{\circ}$, it provides insight into the likely responses of satellites which operate at shallower angles, such as ASCAT which operates close to $40^{\circ}$. For a smooth soil overlying a rough sub-surface we can expect the sub-surface's dominance over the surface return to be enhanced at the shallower operating angle of ASCAT. For the mixed soil, the results are likely to be specific to the particular scenario. However, the experimental results are suggestive of an increasing backscatter anomaly with increasing incidence angle. Some simple considerations further support this; backscatter is always expected to decrease with increasing, shallower incidence angles $[14,15]$. The surface viewing angle is directly set by the geometry to the satellite, whereas the subsurface illumination angle is the refracted wave which is always at a steeper angle. For the sandy soil medium used here, the sub-surface features would experience the $40^{\circ}$ surface illumination at a refracted angle of $24^{\circ}$ for a dry soil, and at a steeper angle still with moisture present.

\section{CONCLUSIONS}

Low moisture contents allow significant penetration of C-band microwaves into a soil, leading to the possibility of substantial sub-surface returns. The laboratory results tell the story that in the real world, sandy soils possessing a distinct, brightly reflecting sub-surface - such as a bedrock or rocky layer could produce an anomalous backscatter drying signal in which backscatter increases with moisture decrease. Its dominance in the backscatter record will be enhanced when 
the overlying soil has a flat surface. Conversely, sandy soils with a rough surface and distributed stony inclusions, will act to obfuscate the sub-surface signal. It seems likely that platforms which operate at incidence angles shallower than explored in this study - such as ASCAT and Sentinel-1 - will have an increased sensitivity to backscatter moisture anomalies. The polarization and angle dependencies of the anomalies may provide sufficient diagnostics to both identify and characterize moisture anomalies. This should allow flagging of anomalous moisture estimates, and their identification with very low moisture states.

\section{ACKNOWLEDGMENT}

KM was supported by a Visiting Scientist Grant for this study on ESA Contract No. 4000112226/14/I-NB. KM is also grateful to the University of Reading for making the Reading Radar Facility available for this work and providing technical support. The authors wish to acknowledge Sebastian Hahn's help in production of Fig. 1.

\section{REFERENCES}

[1] S.I. Seneviratne, T. Corti, E.L. Davin, M. Hirschi, E.B. Jaeger, I. Lehner, B. Orlowsky, and A.J. Teuling, "Investigating soil moistureclimate interactions in a changing climate: a review," Earth Sci. Reviews, vol. 99, pp. 125-161. 2010.

[2] A. K. Prasad, L. Chai, R. P. Singh, and M. Kafatos, "Crop yield estimation model for Iowa using remote sensing and surface parameters," International Journal of Applied Earth Observation and Geoinformation, vol. 8, no. 1, pp. 26-33, Jan. 2006.

[3] W. Crow, G. Huffman, R. Bindlish, and T. Jackson, "Improving satellite-based rainfall accumulation estimates using spaceborne surface soil moisture retrievals," Journal of Hydrometeorology, vol. 10, pp. 199-212, Feb. 2009.

[4] C. Hauck, C. Barthlott, L. Krauss, and N. Kalthoff, "Soil moisture variability and its influence on convective precipitation over complex terrain," Quarterly Journal of Royal Meteorological Society, vol. 137, S1, pp. 42-56, Jan. 2011.

[5] W. Dorigo et al., "ESA CCI Soil Moisture for improved Earth system understanding: State-of-the art and future directions," Remote Sensing of Environment vol. 203, pp.185-215. 2017.

[6] A. L. Barbu, J.-C. Calvet, J.-F. Mahfouf, and S. Lafont, "Integrating ASCAT surface soil moisture and GEOV1 leaf area index into the SURFEX modeling platform: A land data assimilation application over France," Hydrology and Earth System Science., vol. 18, no. 1, pp. 173192, Jan. 2014.

[7] W. Wagner et al., "The ASCAT soil moisture product: A review of its specifications, validation results, and emerging applications", Meteorologische Zeitschrift, vol. 22, no. 1, pp. 5-33, Feb. 2013.

[8] V. Naeimi, K. Scipal, Z. Bartalis, S. Hasenauer, and W. Wagner, "An improved soil moisture retrieval algorithm for ERS and MetOp scatterometer observations," IEEE Trans. Geoscience \& Remote Sensing, vol. 47, no. 7, pp. 1999-2013, Jul. 2009.

[9] A. Dostálová, M. Doubková, D. Sabel, B. Bauer-Marschallinger, and W. Wagner, "Seven Years of Advanced Synthetic Aperture Radar (ASAR) Global Monitoring (GM) of Surface Soil Moisture over Africa," Remote Sensing, vol. 6, pp. 7683-7707, 2014.

[10] D.B. Lindell, and D. Long, "High-Resolution Soil Moisture Retrieval With ASCAT," IEEE Geoscience and Remote Sensing Letters, vol. 13, no. 7, Jul. 2016.

[11] S. Hahn, T. Melzer, and W. Wagner, "Error assessment of the initial near real-time MetOp ASCAT surface soil moisture product," IEEE Trans. Geoscience \& Remote Sensing, vol. 50, no 7, pp. 2556-2565, Jul. 2012.
[12] M. Rodell et al., "The Global Land Data Assimilation System," Bulletin of the American Meteorological Society, vol. 85, no. 3, pp. 381-394, March 2004.

[13] F. T. Ulaby, "Radar measurement of soil moisture content," IEEE Trans. Antennas \& Propagation, vol. 22, no. 2, pp. 257-265, Mar. 1974.

[14] Y. Oh, K. Sarabandi, and F. T. Ulaby, "An empirical model and an inversion technique for radar scattering from bare soil surfaces," IEEE Trans. Geoscience \& Remote Sensing, vol. 30, no. 2, pp. 370-382, Mar. 1992.

[15] P. C. Dubois, J. van Zyl, and E. T. Engman, "Measuring soil moisture with imaging radar," IEEE Trans. Geoscience \& Remote Sensing, vol. 33, no. 4, pp. 916-926, Jul. 1995.

[16] K. Morrison, "Mapping Subsurface Archaeology with SAR," Archaeological Prospection, vol. 20, no. 2, pp.149-160, May 2013.

[17] P.-W. Liu, J. Judge, R. D. DeRoo, A. W. England, T. Bongiovanni, and A. Luke, "Dominant backscattering mechanisms at L-band during dynamic soil moisture conditions for sandy soils," Remote Sensing of Environment, vol. 178, pp. 104-112. Jun. 2016.

[18] K. Morrison and J.C. Bennett, "Tomographic Profiling - A Technique for Multi-Incidence-Angle Retrieval of the Vertical SAR Backscattering Profiles of Biogeophysical Targets," IEEE Transactions on Geoscience and Remote Sensing, vol. 52, no. 2, pp.1350-1355, Apr. 2013.

[19] A. Edwards-Smith, K. Morrison, S. Zwieback, and I. Hajnsek, "Verification of the virtual bandwidth SAR (VB-SAR) scheme for centimetric resolution subsurface imaging from space." Trans. on Geoscience and Remote Sensing, vol. 56, no. 1, pp. 25-34. Oct. 2017.

[20] K. Morrison, J. C. Bennett, G. Cookmartin, A. J. McDonald, A. Race, and S. Quegan "Three-Dimensional X-band SAR Imaging of a Small Conifer Tree," International Journal of Remote Sensing, vol. 22, pp.705-710, 2001.

[21] K. Morrison. and J.C. Bennett, "Virtual Bandwidth SAR (VB-SAR) For Centimetric-Scale Sub-Surface Imaging From Space," International Journal of Remote Sensing, vol. 36, pp.1789-1808, 2015.

[22] K.S. Chen, S.K. Yen, W.P. Huang, "A simple model for retrieving bare soil moisture from radar-scattering coefficients," Remote Sensing of Environment, vol. 54, no. 2, pp. 121-126, Nov. 1995.

[23] Y. Oh, "Quantitative retrieval of soil moisture content and surface roughness from multipolarized radar observations of bare soil surfaces," IEEE Trans. Geosci. Remote Sens., vol. 42, no. 3, pp. 596601, Mar. 2004.

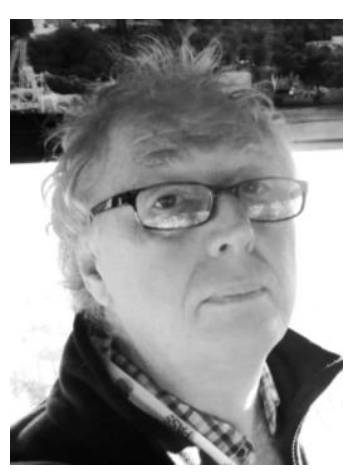

Keith Morrison (M'96) received a B.Sc. in physics with astrophysics from the University of Leicester, Leicester, U.K. in 1983, and a Ph.D. in astronomy and astrophysics from the University of St. Andrews, St. Andrews, U.K. in 1987. He was with the British Antarctic Survey 1987-1994, Sheffield University 19942000, DERA/QinetiQ Malvern 20002002, and Cranfield University 20022016. The latter included a four-month sabbatical based in the Microwaves Institute at the German Aerospace Center, Wessling. Since 2016, he has been a professor within the Meteorology Department at the University of Reading, UK. His main research interest is the development and application of groundbased SAR imaging and signal processing techniques applied to environmental remote sensing. He has carried out extended fieldwork campaigns on crops, forestry, and snow across Europe, synergistically with indoor laboratory studies. He won an annual best publication award in 2001 from Taylor \& Francis Publishing for one of the first demonstrations of 3D SAR tomography, and was 
previously a recipient of NASA's Group Achievement Award in 1998.

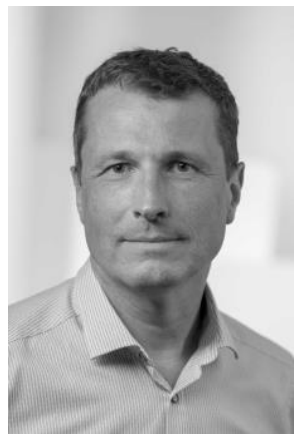

Wolfgang Wagner (M'98-SM'07) was born in Austria in 1969. He received the Dipl.-Ing. degree in physics and the Dr.techn. degree in remote sensing from TU Wien, Austria, in 1995 and 1999 respectively. In support of his master and $\mathrm{PhD}$ studies he received fellowships to carry out research at NASA, ESA, and the EC Joint Research Centre. From 1999 to 2001 he was with DLR. In 2001 he was appointed professor for remote sensing at TU Wien. Since 2012 he has been head of the Department of Geodesy and Geoinformation of TU Wien. He is cofounder and senior scientist at the EODC Earth Observation Data Centre. His main research interest is to gain physical understanding of the mechanisms driving the interaction of electromagnetic waves with the land surface. He has developed models for retrieving soil moisture, biomass, and other land surface variables from scatterometer, SAR and full-waveform lidar observations. He is a member of the EUMETSAT/ESA Science Advisory Group for METOP-SG SCA. From 2008 to 2012 he served as ISPRS Commission VII President, from 2009 to 2011 as editor-in-chief of the Open Access Journal "Remote Sensing", and from 2016 to 2019 as chair of the GCOS/WCRP Terrestrial Observation Panel for Climate. He is a recipient of the ISPRS Frederick J. Doyle Award for his scientific contributions in active remote sensing. 